\title{
A deliberately swallowed foreign body: money package
}

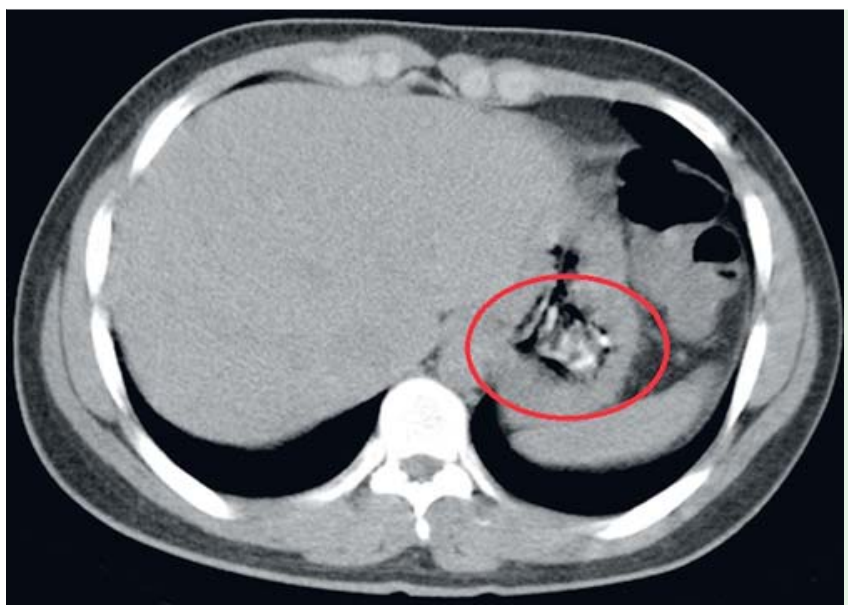

Fig. 1 Abdominal computed tomography showed the foreign body in the stomach.
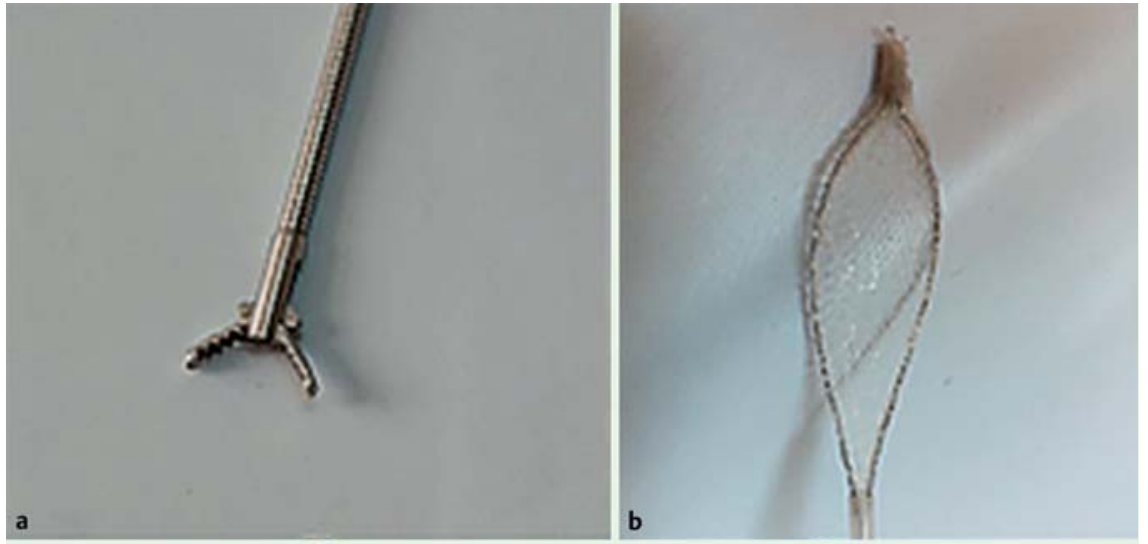

c

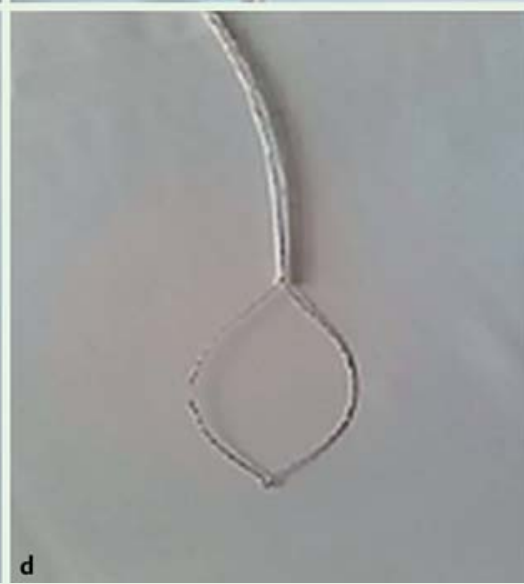

Fig. 3 Endoscopy instruments used in attempts to retrieve the money bundle. a Alligator forceps. b Retrieval net. c Tripod foreign body forceps. d Polypectomy snare.

Wars have always resulted in catastrophic consequences for the communities involved. Often, people are forced to leave their countries in search of a better life. Because the journey ahead is long and of unknown duration, people take small valuables with them, including jewelry and money.

Herein, we describe the endoscopic retrieval of a money package, which had been deliberately ingested by a refugee for safe keeping. Ingestion of a foreign body is

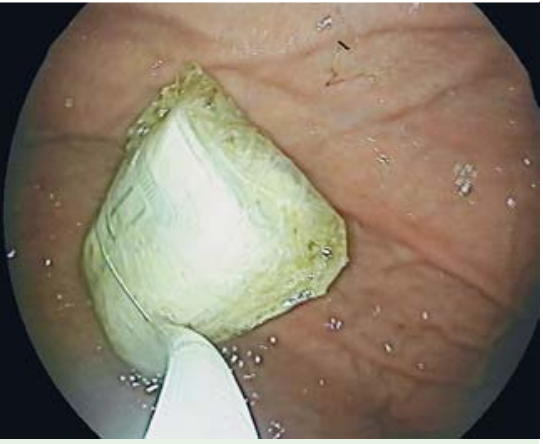

Fig.2 Gastroduodenoscopy revealed the money bundle, which was wrapped inside a nylon bag, in the antrum.

common in childhood and in adults affected by excess alcohol intake, but ingestion is usually accidental in these cases.

A 23-year-old Syrian man was admitted to the emergency department complaining of epigastric fullness. The history revealed that he had swallowed a bundle of dollars wrapped inside a nylon bag. He was a refugee who had fled his country because of the ongoing war. His vital signs were within normal limits. Physical examination revealed no abnormalities. Plain thoracoabdominal radiogram did not show any abnormalities. Computed tomography showed a foreign body in the distal stomach ( $\bullet$ Fig. 1 ).

The patient underwent gastroduodenoscopy and the package was seen in the antrum ( $\bullet$ Fig.2). The package was difficult to retrieve because it was quite large and the endoscopic devices were not strong enough to grasp it. Initial attempts at grasping the package with an alligator forceps failed ( Fig.3a). A net, $23 \mathrm{~mm}$ in diameter, was too small to grasp the package ( $\bullet$ Fig.3b). Tripod foreign body forceps could not exert enough force around the package to pull it out $(-$ Fig.3c). Finally, a polypectomy snare, $60 \mathrm{~mm}$ in diameter, was used to grasp the package tightly ( $\bullet$ Fig.3d). However, when the package was pulled horizontally, it was not possible to pass it through the gastroesophageal junction. The package was finally removed by pulling it parallel to the endoscopic axis. The package measured $40 \times$ $25 \mathrm{~mm}$ in size, and contained a total of 1000 dollars ( Fig.4), which was returned to the patient. 


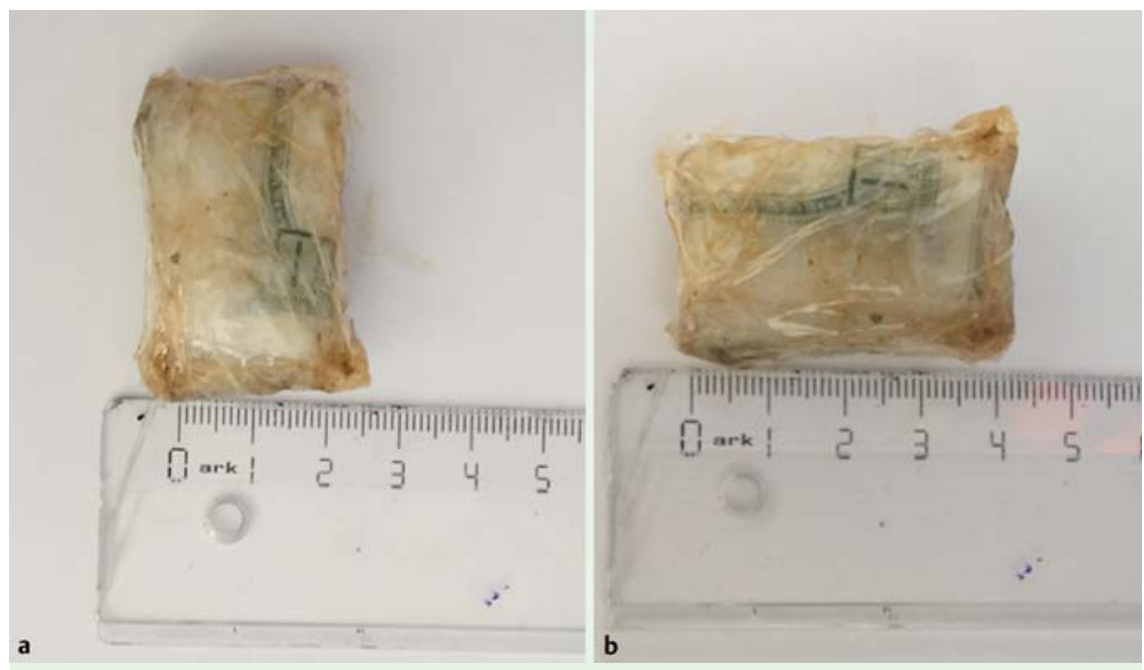

Fig. 4 The money bundle wrapped inside a nylon bag after endoscopic removal. The foreign body was $25 \times 40 \mathrm{~mm}(\mathbf{a}, \mathbf{b})$.

Deliberate foreign body ingestion is uncommon and the current case is a reflection of the desperation felt by the victims of war, saving what small valuables they can carry, by whatever means, even if it means risking their health. The American Society for Gastrointestinal Endoscopy guideline recommends the removal of all foreign bodies in the stomach that are bigger than $25 \mathrm{~mm}$ in size [1].
A package as big as $40 \times 25 \mathrm{~mm}$ in size cannot pass through the gastrointestinal tract spontaneously, and poses a risk of obstruction or perforation. The best approach for gastrointestinal foreign bodies is prompt removal with the best available devices, and by an experienced endoscopist.

Endoscopy_UCTN_Code_CCL_1AB_2AF

Competing interests: None
Seval Akay¹, Süleyman Günay², Ömer Burçak Binicier², Zehra Betül Paköz ${ }^{2}$, Harun Akar ${ }^{1}$

${ }^{1}$ Department of Internal Medicine, Izmir Tepecik Education and Research Hospital, Izmir, Turkey

2 Department of Gastroenterology, Izmir Tepecik Education and Research Hospital, Izmir, Turkey

\section{Reference}

1 Ikenberry S, Jue T, Anderson $M$ et al. ASGE standards of Practice committee. Management of ingested foreign bodies and food impactions. Gastrointest Endosc 2011; 73 : 1085-1091

\section{Bibliography}

DOI http://dx.doi.org/

10.1055/s-0035-1569668

Endoscopy 2015; 47: E602-E603

(c) Georg Thieme Verlag KG

Stuttgart · New York

ISSN 0013-726X

\section{Corresponding author}

\section{Seval Akay, MD}

Department of Internal Medicine Izmir Tepecik Education and Research Hospital Kazım Dirik Mah. 157.Sk No:5

Izmir 35100

Turkey

Fax: +90-232-4335227

drsevalsekerler@hotmail.com 